\title{
Linkage of the Structural Gene for Uroporphyrinogen I Synthase to Markers on Mouse Chromosome 9 in a Cross Between Feral and Inbred Mice
}

\author{
Tammy K. Antonucci, ${ }^{1}$ Verne C. Chapman, ${ }^{2}$ and Miriam H. Meisler ${ }^{1,3}$ \\ Received 23 Oct. 1981-Final 23 Feb. 1982
}

The Ups locus has been mapped to mouse chromosome 9 in a three-point cross. The observed gene order is centromere-Ups-15-Mpi-1-22-Mod-1. Ups is unlinked to Lv, which encodes the previous enzyme in the heme biosynthesis pathway. Feral mice collected at Skive, Denmark, have been characterized at several biochemical loci; multiple differences from inbred strains make this a useful stock for linkage analysis.

KEY WORDS: heme; porphobilinogen deaminase; Skive; isozymes.

\section{INTRODUCTION}

Uroporphyrinogen I synthase (porphobilinogen deaminase; EC 4.3.1.8) is the third of eight enzymes in the biosynthetic pathway leading to heme production. These enzymes are ubiquitous among mammalian tissues, and genetic deficiency of any one of them results in human disease (Meyer and Schmid, 1978). Until now, the linkage relationships among the structural genes for this pathway in higher organisms have not been studied. The $L v$ locus in the mouse, encoding the second enzyme in the pathway, porphobilinogen synthase, has been assigned to mouse chromosome 4 (Hutton and Coleman,

\footnotetext{
Supported by USPHS Grants GM 24872 and GM 19521.

' Department of Human Genetics, University of Michigan Medical School, Ann Arbor, Michigan 48109.

${ }^{2}$ Department of Molecular Biology, Roswell Park Memorial Institute, Buffalo, New York 14263.

${ }^{3}$ To whom correspondence should be addressed.
} 
1969). The recent identification of a variant at the mouse Ups locus encoding uroporphyrinogen I synthase (Meisler and Carter, 1980) provided the opportunity to investigate the linkage relationship between the $L v$ and the Ups loci.

Structural variants of uroporphyrinogen I synthase are rare in mouse and human populations (Meisler and Carter, 1980). A basic variant of the human enzyme was observed in 4 individuals among 951 surveyed. No variants were found among 17 inbred strains examined, but an acidic variant was detected in feral mice Mus musculus musculus, collected in Denmark. We have used this acidic variant to determine the chromosomal location of mouse $U p s$, in a cross between the feral mice and a subline of inbred C57BL/6J mice.

Isoelectric focusing followed by staining for enzyme activity was used to identify structural variants. The method reveals the presence of multiple UPS isomers in mammalian cells. The isomers are produced by the sequential binding of one to four molecules of the acidic substrate, porphobilinogen, by the monomeric enzyme (Anderson and Desnick, 1980; Meisler et al., 1981; Jordan and Berry, 1981). The difference in isoelectric points of the human and mouse isozymes in hybrid cell lines made it possible to assign the human Ups locus to chromosome region $1 \mathrm{lq} 13 \rightarrow$ ter (Meisler et al., 1980, 1981). In the present work, the chromosomal location of the mouse locus was investigated.

\section{MATERIALS AND METHODS}

Animals. Feral Mus musculus musculus (Skive) used in this study were collected by J. T. Nielsen, University of Aarhus, at Skive, Denmark. They were sent to RPMI in 1973, where they were established in the laboratory as a random-breeding stock. They have been maintained as a closed colony since that time. A congenic strain, C57BL/6J.le $r d G u s^{h}$, was established by Dr. E. Russell, the Jackson Laboratory, Bar Harbor, Maine. The stock was sent to RPMI in 1973. It has been maintained as an inbred strain since that time. In this article, it is designated C57BL/6 J-1e.

Three $F_{1}$ litters were obtained from a cross between a Skive female and a C57BL/6J-1e male. Six $\mathrm{F}_{1}$ females, heterozygous at $U p s$, were mated with $\mathrm{C} 57 \mathrm{BL} / 6 \mathrm{~J}-1 \mathrm{e}$ males to produce the backcross generation which was analyzed. The segregating markers used in this study are listed in Table I.

YBR/Ki mice were purchased from the Kirschbaum Memorial Mouse Colony, Rootstown, Ohio. The PAC strain is the c line derived from a colony of mice that were trapped near Philadelphia, Pa., by Dr. James Connor. He established several inbred strains from these populations. PAC is one of those lines sent to RPMI in 1974 at $F_{20}$. This line has been maintained as an inbred strain at RPMI using brother-sister matings. All other inbred mice were purchased from the Jackson Laboratory. In most cases, individual mice from each strain were typed. CD 1 mice were obtained from the Charles River Breeding Lab, North Wilmington, Mass. 
Table I. Loci Examined in Backcross Animals

\begin{tabular}{lccc}
\hline & & \multicolumn{2}{c}{ Alleles } \\
\cline { 3 - 4 } Locus & Chromosome & C57BL/6J-1e & Skive \\
\hline Ups & - & $\mathrm{a}$ & $\mathrm{b}$ \\
$A$ & 2 & $\mathrm{a}$ & $\mathrm{e}$ \\
le & 5 & $\mathrm{~b}$ & + \\
Gpi-1 & 7 & $\mathrm{~b}$ & $\mathrm{a}$ \\
Mod-I & 9 & $\mathrm{~b}$ & $\mathrm{a}$ \\
Mpi-1 & 9 & & $\mathrm{a}$ \\
\hline
\end{tabular}

Erythrocytes from MOL/JA, an inbred strain derived from M.m. molossinus by Dr. T. Roderick, Jackson Laboratory, were obtained from Dr. J. Hilgers, Netherlands Cancer Institute.

Sample Preparation. Erythrocyte lysates were prepared as previously described (Meisler and Carter, 1980). Livers were homogenized in 3 vol of $0.25 \mathrm{M}$ sucrose in $50 \mathrm{~mm}$ Tris- $\mathrm{HCl}, p \mathrm{H} \cdot 7.5$, with a Polytron homogenizer (Brinkman). Kidneys were homogenized in 2 vol distilled $\mathrm{H}_{2} \mathrm{O}$. All homogenates were centrifuged at $28,000 \mathrm{~g}$ for $30 \mathrm{~min}$ on the day of electrophoretic analysis.

Electrophoresis and Staining. Isoelectric focusing was carried out on

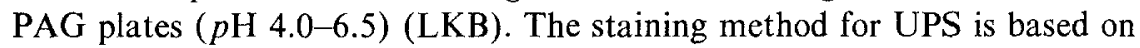
the fluorescence of the product (Meisler and Carter, 1980). Isozymes of glucose phosphate isomerase-1 (GPI-1), mannose phosphate isomerase-1 (MPI-1), and soluble malate dehydrogenase-1 (MOD-1) were separated by electrophoresis on Titan III cellulose acetate plates $(60 \times 75 \mathrm{~mm})$ (Helena Laboratories, Tex.) in $25 \mathrm{~mm}$ Tris, $200 \mathrm{~mm}$ glycine buffer, $p \mathrm{H} 8.5$. Electrophoresis was carried out at $200 \mathrm{~V}$ for $90 \mathrm{~min}$, except that $120 \mathrm{~min}$ was required for MOD-1. GPI-1 was stained with fructose-6-phosphate as substrate in a $2 \%$ agar overlay (Carter and Parr, 1967). MPI-1 was stained with the substrate mannose-6-phosphate in a 2\% agar overlay (Nichols et al., 1973). MOD-1 was detected by the method of Holmes (1979).

\section{RESULTS}

Segregation of Ups Alleles. UPS phenotypes were determined by isoelectric focusing of hemolysates followed by staining for enzyme activity. Four or more enzyme isomers are visible in each hemolysate (Fig. 1). It is convenient to classify phenotypes on the basis of the major erythrocyte isomers (designated $a$ and $b$ in Fig. 1) since the minor components are not well resolved by this $p \mathrm{H}$ gradient. $\mathrm{C} 57 \mathrm{BL} / 6 \mathrm{~J}-1 \mathrm{e}$ mice have the UPS A phenotype (Fig. 1, Lane 1), while the Skive mouse in our cross was UPS B (Fig. 1, Lane 


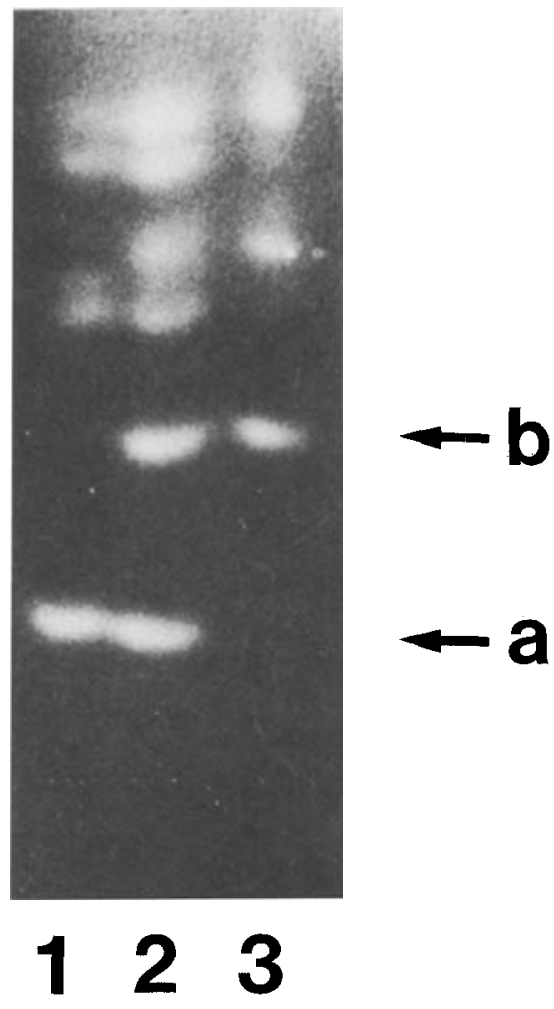

Fig. 1. Uroporphyrinogen I synthase phenotypes. Twenty-five-microliter samples of erythrocyte lysates were focused on $11-\mathrm{cm}$ PAG plates, $p \mathrm{H} 4.0-6.5$, followed by staining to detect UPS activity. Lane 1, C57BL/6J-1e; Lane 2, (Skive $\times$ C57BL/6J-1e) F ; Lane 3, Skive. Multiple bands of activity are encoded by a single locus, as discussed in the Introduction. ( $A$ faint band in the position of the $b$ allele product is occasionally observed in $\mathrm{C} 57 \mathrm{BL} / 6 \mathrm{~J}$ mice. In such samples the intensity of the b-like band is always much less than that of the a band, which distinguishes the pattern from that of heterozygotes.)

3). Both sets of parental isomers are present in $F_{1}$ heterozygotes, in apparently equal amounts (Fig. 1, Lane 2). Backcrosses of heterozygous females to C57BL/6J-1e males produced mice of two phenotypes, UPS A and UPS A/B; the ratio of the two types (24:30) did not differ significantly from $1: 1\left(\chi^{2}=\right.$ $0.67 ; P \cong 0.45$ ). Comparable numbers of males and females were present among the homozygotes and heterozygotes in the backcross generation. The results are consistent with the segregation of two codominantly expressed alleles at a single autosomal locus. This locus is designated Ups, with the alleles $U p s^{a}$ producing the UPS A phenotype common to C $57 \mathrm{BL} / 6 \mathrm{~J}$ and other inbred strains and $U p s^{b}$ found in feral M. m. musculus (Skive). ${ }^{4}$

Biochemical evidence indicates that the minor UPS isomers visible on the gels are stable complexes of the same monomeric enzyme with variable numbers of substrate molecules (Anderson and Desnick, 1980; Meisler et al., 1981; Jordan and Berry, 1981). If this is correct, then all isomers should

\footnotetext{
${ }^{4}$ The original allele designations, $U p s^{l}$ and $U p s^{2}$ (Meisler and Carter, 1980) have been changed to conform to the recommendations of the Committee on Standardized Genetic Nomenclature for Mice (1979).
} 
cosegregate as a unit in the backcross. In agreement with this expectation, minor acidic isomers segregated with the $U p s^{b}$ allele and could be detected in $U p s^{a / b}$ heterozygotes in the backcross generation but not in the $U p s^{a / a}$ individuals (Fig. 2).

Linkage Analysis. The Ups alleles did not cosegregate with the visible markers Agouti or light ear (Table II). The human UPS locus is known to be syntenic with the $\beta$-globin genes (Meisler et al., 1980). Since mouse GPI-1 is linked to the mouse globin gene complex region, and since a GPI-1 variant is segregating in this cross, we analyzed GPI-1 in the backcross animals. No linkage was observed (Table II). It subsequently became clear that the human $\beta$-globin and UPS loci are located on different arms of chromosome 11 (Meisler et al., 1981), so that linkage in mice would not be anticipated (Lalley et al., 1978).

Significant linkage was observed in a three-point cross with the chromosome 9 markers Mod-1 and Mpi-1. The frequencies of parental and recombi-

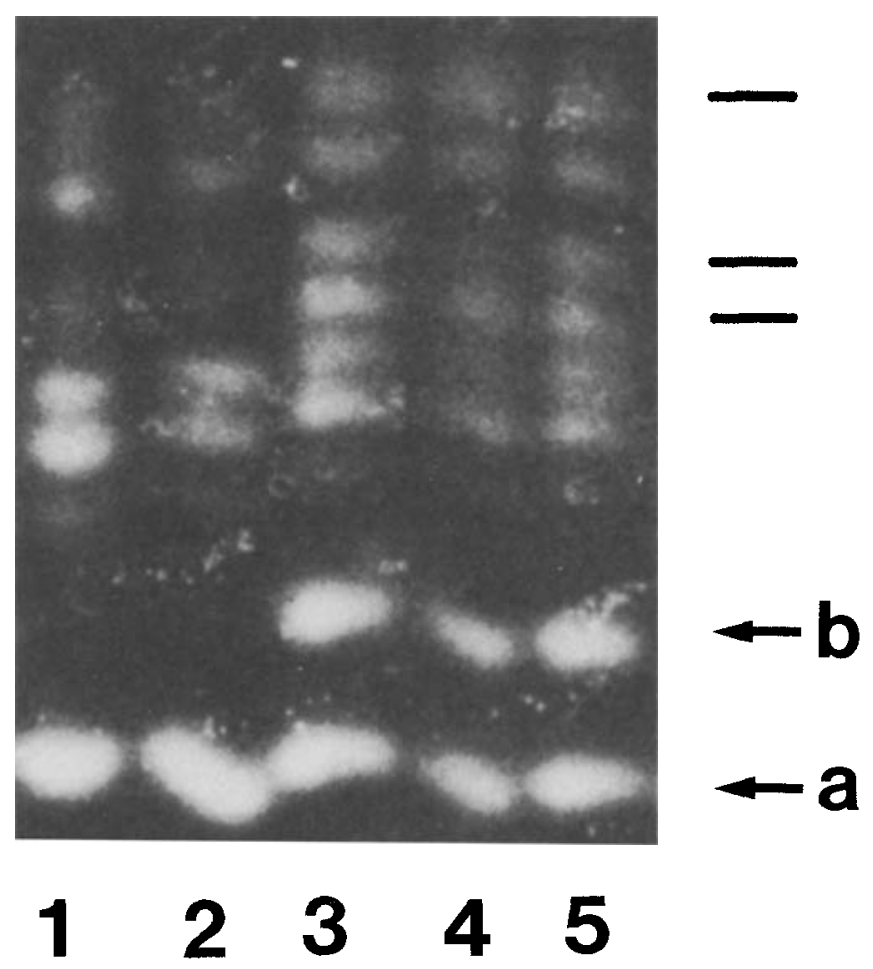

Fig. 2. Cosegregation of UPS isomers in the backcross generation. Five individuals are shown, with UPS phenotypes $A$ (Lanes 1 and 2) and A/B (Lanes 3-5). In addition to the major $\mathrm{b}$ allele product, the heterozygotes contain three minor isomers (indicated by markers) which cosegregate with the major band. 
Table II. Segregation of Alleles at Ups, with Alleles at the Agouti, le, and Gpi-1 Loci in Progeny of the Cross (Skive $\times$ C57BL/6J-1e) $\mathrm{F}_{1} \times$ C57BL/6J-1e

\begin{tabular}{lcc}
\hline \multicolumn{1}{c}{ Locus } & Chromosome & $\begin{array}{c}\text { Frequency of recombination } \\
\text { with } U p s \pm \mathrm{SE}\end{array}$ \\
\hline Agouti & 2 & $\mathbf{2 4 / 5 4}=\mathbf{0 . 4 4} \pm \mathbf{0 . 0 6 7}$ \\
le & 5 & $\mathbf{2 3} / \mathbf{5 4}=\mathbf{0 . 4 3} \pm \mathbf{0 . 0 6 7}$ \\
Gpi-1 & 7 & $\mathbf{3 1} / \mathbf{5 4}-\mathbf{0 . 5 7} \pm \mathbf{0 . 0 6 7}$ \\
\hline
\end{tabular}

Table III. Segregation of Alleles at Three Linked Loci on Chromosome 9 in the Backeross Generation

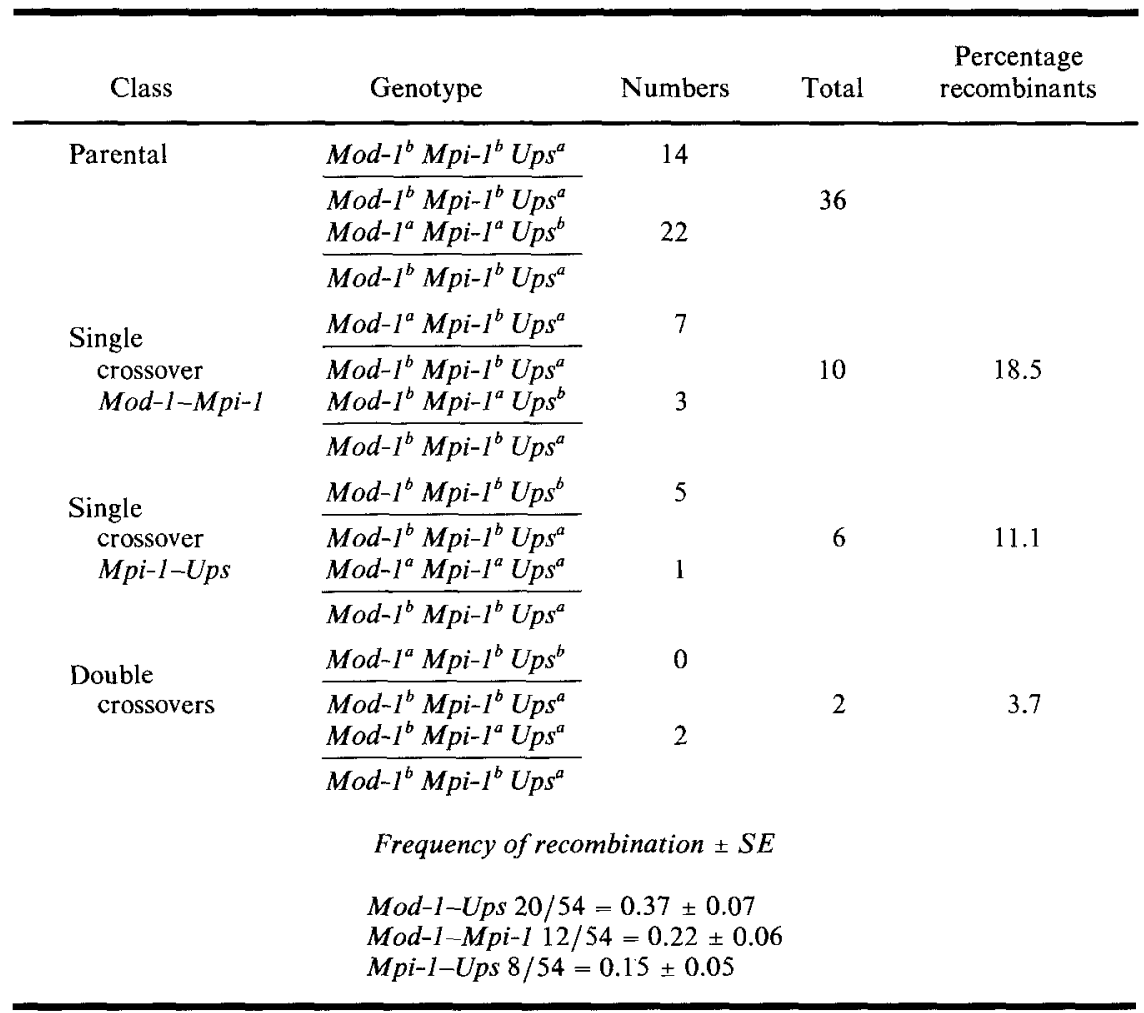


nant animals are presented in Table III. There were 20/54 recombinants between $U p s$ and $M o d-1$ and 8/54 recombinants between Ups and $M p i-1$. The resulting gene order and map distances are centromere- $U p s-15-M p i-1-$ 22-Mod-1. The frequency of double recombinants was $2 / 54=0.037$; the expected frequency is 0.033 .

Additional Electrophoretic Variants in Skive Mice. By comparisons with known alleles in various inbred strains, the Skive population was found to carry the following alleles: $A d h-1^{a}, D i p-1^{b}, E s-2^{a}, E s-3^{b}, E s-10^{b}, G p d-1^{b}, G u s^{b}$, $I d-1^{b}, P g m-I^{b}, P g m-2^{b}$, and Tam- $I^{b}$. These biochemical markers, which with the exception of $G u s^{b}$ all differ from the C57BL/6J alleles, make Skive a useful stock for linkage analysis.

Strain Survey. In a previous study, 17 inbred strains were found to carry the $U p s^{\alpha}$ allele (Meisler and Carter, 1980). Hemolysates from 18 additional strains have now been tested. The following 16 strains carry the $U p s^{a}$ allele: ABY/Sn, AU/SsJ, BDP/J, C57BL/10J, C57L/J, DBA/1J, DBA/2J, I/LnJ, LG/J, MA/MyJ, P/J, PAC, RF/J, Sm/J, YBR/Ki, and 129/SvJ. In addition, 13 individuals from the outbred CD-1 stock were also homozygous for the $U p s^{a}$ allele. The $U p s^{b}$ allele has been identified in two inbred strains, $\mathrm{LP} / \mathrm{J}$ and $\mathrm{MOL} / \mathrm{JA}$, which is derived from M. m. molossinus.

\section{DISCUSSION}

Linkage of the Ups locus to two segregating markers, Mod-1 and Mpi-1, enabled us to determine the approximate location of this new biochemical marker on mouse chromosome 9. Ups is located close to the Lap-I and Thy-I loci, approximately $20 \mathrm{cM}$ distal to the centromere of chromosome 9 . The locus is thus unlinked to $L v$ on chromosome 4 , demonstrating that the enzymes of heme biosynthesis are not clustered in the mammalian genome.

Our estimate of the distance between Mod-1 and Mpi-1,22 $\pm 6 \mathrm{cM}$, is in good agreement with the $19 \mathrm{cM}$ reported by Nichols et al. (1973) based on their observation of 27 recombinants among 142 backcross progeny.

Several examples of conserved chromosome regions have emerged from comparison of human and mouse linkage groups (Lalley et al., 1978; Pearson et al., 1979). However, in the present case no conservation is evident. The three mouse chromosome 9 loci studied here, Mod-1, Mpi-1, and Ups, are unlinked in the human genome (Chen et al., 1973; Meisler et al., 1980; Heyningen et al., 1975). On the other hand, two markers which are close to Ups on mouse chromosome 9, Lap-1 and Thy-1, have not yet been assigned to human chromosomes. Similarly, the mouse homologues of human ESA-4 and SA11, which are linked to human Ups on the long arm of chromosome 11, have not been mapped in the mouse genome. Our results suggest possible locations for these unmapped loci.

It has been evident for some time that crosses between inbred and feral mice could be useful for linkage analysis, due to the presence of unusual 
biochemical markers in wild mouse populations (Chapman, 1978). This study provides an example of the utility of feral mice for expansion of the mouse linkage map.

\section{ACKNOWLEDGMENT}

We thank Todor Krasteff for advice regarding electrophonetic methods.

\section{REFERENCES}

Anderson, P., and Desnick, R. (1980). Purification and properties of uroporphyrinogen I synthase from human erythrocytes. J. Biol. Chem. 255:1993.

Carter, N. D., and Parr, C. W. (1967). Isoenzymes of phosphoglucose isomerase in mice. Nature 216:511.

Chapman, V. M. (1978). Biochemical Polymorphisms in Wild Mice. In Morse, H. C. (ed.), Origins of Inbred Mice, Academic Press, London, pp. 555-568.

Chen, T. R., McMorris, F. A., Creagan, R., Ricciuti, F., Tischfield, J., and Ruddle, F. H. (1973). Assignment of the genes for malate oxidoreductase decarboxylating to chromosome 6 and peptidase B and lactate dehydrogenase B to chromosome 12 in man. Am. J. Hum. Genet. 25:200.

Committee on Standardized Genetic Nomenclature for Mice (1979). New rules for nomenclature of genes, chromosome abnormalites, and inbred strains. Mouse News Lett. 61:4.

Holmes, R. S. (1979). Genetics and ontogeny of alcohol dehydrogenase isozymes in the mouse: Evidence for a cis-acting regulator gene $(A d t-1)$ controlling $\mathrm{C} 2$ isozyme expression in reproductive tissues and close linkage of $A d h-3$ and $A d t-1$ on chromosome 3. Biochem. Genet. 17:461.

Hutton, J. J., and Coleman, D. L. (1969). Linkage analyses using biochemical variants in mice. II. Levulinate dehydratase and autosomal glucose-6-phosphate dehydrogenase. Biochem. Genet. 3:517.

Jordan, P. M., and Berry, A. (1981). Mechanism of action of porphobilinogen deaminase. Biochem. J. 195:177.

Lalley, P. A., Minna, J. D., and Francke, U. (1978). Conservation of autosomal gene synteny groups in mouse and man. Nature 274:160.

Meisler, M. H., and Carter, M. L. C. (1980). Rare structural variants of human and murine uroporphyrinogen I synthase. Proc. Natl. Acad. Sci. USA 77:2848.

Meisler, M. H., Wanner, L., Eddy, R. E., and Shows, T. B. (1980). The UPS locus encoding uroporphyrinogen I synthase is located on human chromosome 11. Biochem. Biophys. Res. Commun. 95:170.

Meisler, M. H., Wanner, L., Kao, F. T., and Jones, C. (1981). Localization of the uroporphyrinogen I synthase locus to human chromosome region $11 \mathrm{q} 13 \rightarrow$ ter and interconversion of enzyme isomers. Cytogenet. Cell Genet. 31:124.

Meyer, U. A., and Schmid, R. (1978). The porphyrias. In Stanbury, J. B., Wyngaarden, J. B., and Fredrickson, D. S. (eds.), Metabolic Basis of Inherited Disease, McGraw-Hill, New York, pp. 1166-1221.

Nichols, E. A., Chapman, V. M., and Ruddle, F. H. (1973). Polymorphism and linkage for mannosephosphate isomerase in Mus musculus. Biochem. Genet. 8:47.

Pearson, P. L., Roderick, T. H., Davisson, M. T., Garver, J. J., Warburton, D., Lalley, P. A., and O'Brien, S. J. (1979). Report of the committee on comparative mapping. Cytogenet. Cell Genet. 25:82.

van Heyningen, V., Bobrow, M., Bodmer, W. F., Povey, S., Gardner, S. E., and Hopkinson, D. A. (1975). Assignment of the genes for human mitochondrial malate dehydrogenase to chromosome 7 , for mannose phosphate isomerase and pyruvate kinase to chromosome 15 , and, probably, for human esterase-D to chromosome 13 using man-mouse hybrids. Cytogenet. Cell Genet. 14:353. 